\title{
The Effect of Norepinephrine Infusion on Oxygen Delivery and Consumption in the Canine Model
}

\author{
Steven M. Boorstein, M.D., Ronald B. Hirschl, M.D., Michael K. Riley, M.D., Brian S. Kahan, B.S., \\ Karl A. Hultquist, R.R.T., AND Robert H. Bartlett, M.D.
}

Department of Surgery, University of Michigan Medical School, Ann Arbor, Michigan 48109

Submitted for publication November 27, 1991

\begin{abstract}
Norepinephrine (NE) is used clinically to increase oxygen delivery $\left(\mathrm{DO}_{2}\right)$ by increasing cardiac output $(\mathrm{CO})$. The rate of administration of $\mathrm{NE}$ is usually based on frequent measurements of blood pressure (BP) and infrequent measurements of $\mathrm{CO}$ with little regard for oxygen delivery or consumption dynamics. Although the ultimate goal of an inotropic drug is to increase $\mathrm{DO}_{2}$ in excess of metabolic requirements $\left(\mathrm{VO}_{2}\right)$, the effect of $\mathrm{NE}$ on the $\mathrm{DO}_{2} / \mathrm{VO}_{2}$ ratio has not been previously studied. In the present investigation, healthy anesthetized dogs were infused with various doses of intravenous NE. These dosages were chosen to span the range used clinically. NE administration caused a significant primary increase in $\mathrm{VO}_{2}$ which was dose dependent $(P<$ 0.001 ). A similar dose-dependent increase in $\mathrm{DO}_{2}$ was observed $(P<0.001)$. However, the increase in $\mathrm{DO}_{2}$ minimally exceeded the increase in $\mathrm{VO}_{2}$ at lower doses of $\mathrm{NE}$ and the relative increase in $\mathrm{VO}_{2}$ exceeded the change in $\mathrm{DO}_{2}$ at a dose of $0.04 \mu \mathrm{g} / \mathrm{kg} / \mathrm{min}$. Minimal advantage to oxygen utilization physiology at low doses of NE and a potential deleterious effect at a dose of 0.04 $\mu \mathrm{g} / \mathrm{kg} / \mathrm{min}$ were observed, therefore, despite associated increases in mean systemic blood pressure. The effectiveness of NE administration could be most effectively monitored by the mixed venous oxygen saturation $\left(\mathrm{SVO}_{2}\right)$, rather than by intermittent assessment of $\mathrm{BP}$, $\mathrm{CO}$, or $\mathrm{DO}_{2}$. Even though values for $\mathrm{SVO}_{2}$ and $\mathrm{CO}$ do track closely for the dose of drug administered, $\mathrm{SVO}_{2}$ is a more accurate summation of all components of oxygen consumption and delivery and can be easily and continuously monitored. 1994 Academic Press, Inc.
\end{abstract}

\section{INTRODUCTION}

Norepinephrine (NE) has direct inotropic and $\alpha$-mediated pressor effects. Its role in reversing hypotension and in treating cardiac failure has been well documented $[1,2]$. NE is used clinically to increase systemic oxygen delivery $\left(\mathrm{DO}_{2}\right)$ by increasing cardiac output. Its rate of administration is usually based upon frequent measurements of blood pressure, in addition to infrequent mea- surements of cardiac output, with little regard for the effects upon oxygen consumption $\left(\mathrm{VO}_{2}\right)$. The ultimate goal of inotropic drugs, though, is to increase $\mathrm{DO}_{2}$ in excess of $\mathrm{VO}_{2}$.

Only recently has the relationship between both $\mathrm{DO}_{2}$ and $\mathrm{VO}_{2}$ been examined [3-7]. Cilley et al. documented a linear relationship between $D \mathrm{O}_{2}$ and $\mathrm{VO}_{2}$ at low levels of delivery (below a critical $D^{2} / \mathrm{OO}_{2}$ ratio point). At higher levels of delivery, $\mathrm{VO}_{2}$ was found to be independent of $\mathrm{DO}_{2}$. Under normal physiologic conditions in mammals, oxygen delivery exceeds oxygen consumption by a factor of 4 or 5 to 1 [6]. At very low $D \mathrm{O}_{2} / V \mathrm{O}_{2}$ ratios, tissue oxygen needs may not be met. To be effective, an inotrope should simultaneously increase $D_{2}$ in excess of $\mathrm{VO}_{2}$. The effect of $\mathrm{NE}$ on the $\mathrm{DO}_{2} / \mathrm{VO}_{2}$ ratio has not been studied. Thus, this investigation examined, in a canine model, the effects of $\mathrm{NE}$ on total body $\mathrm{DO}_{2}$ and $\mathrm{VO}_{2}$ while independently measuring these values at several doses to determine norepinephrine's effects on the $\mathrm{DO}_{2} / \mathrm{VO}_{2}$ ratio. The dosages used were chosen to span the range used clinically. The mixed venous oxygen saturation $\left(\mathrm{SVO}_{2}\right)$, mean systemic blood pressure (MSBP), and cardiac output ( $\mathrm{CO}$ ), parameters typically utilized for dosing $\mathrm{NE}$, were additionally examined to observe their accuracy as a reflection of the $D_{2} / \mathrm{OO}_{2}$ ratio.

\section{METHODS}

Five male mongrel canines weighing from 12 to $17.5 \mathrm{~kg}$ were fasted for $12 \mathrm{hr}$ and then anesthetized with $30 \mathrm{mg} /$ $\mathrm{kg}$ pentobarbital sodium. Additional pentobarbital was administered during the experiment, as needed, to maintain clinical sedation. The animals were then intubated with a cuffed endotracheal tube. The dogs were ventilated with an $F_{\mathrm{i}} \mathrm{O}_{2}$ of 0.21 in the supine position with a closed-circuit spirometry system and monitored with a Hewlett-Packard 47210A capnometer to maintain the end-tidal $\mathrm{CO}_{2}$ between 35 and $40 \mathrm{~mm} \mathrm{Hg}$. The core body temperature was maintained between 37.5 and $38.5^{\circ} \mathrm{C}$ with a pump water heater and heating pad. The animal was stabilized for $45 \mathrm{~min}$ after instrumentation before the onset of each experiment. 
An Oximetrix catheter (Mountain View, CA) was placed in the right internal carotid artery to draw blood samples and to monitor systemic blood pressures. An additional Oximetrix catheter was placed in the pulmonary artery via the right external jugular vein. This was used to measure core body temperature, pulmonary artery pressures, and pulmonary capillary wedge pressures (PCWP) as well as to infuse the NE (proximal lumen) and to obtain mixed-venous blood samples (distal lumen). An 8-French catheter was also introduced into the right external jugular vein for administration of lactated Ringers (LR) solution to maintain the PCWP above 8 $\mathrm{mm} \mathrm{Hg}$ before administering the NE. In addition, iced saline was injected through this to measure the $\mathrm{CO}$ via thermodilution assessment. A Sorenson Research (Model 03950-00; Salt Lake, UT) cardiac output computer was used to calculate the CO. Measurements were made using 5-ml injections of iced saline until the readings stabilized (three in a row with less than $10 \%$ deviation from the first). The oxygen delivery was standardized per unit weight using the formula $\mathrm{DO}_{2}=[\mathrm{CO} *(\mathrm{~g}$ $\mathrm{Hb} / \mathrm{dl}$ blood $* 1.39 \mathrm{ml} \mathrm{O} \mathrm{O}_{2} * \mathrm{Hb}$ saturation $)+(0.003 \mathrm{ml}$ $\mathrm{O}_{2} / \mathrm{dl} \mathrm{blood} / \mathrm{mm} \mathrm{Hg} * \mathrm{PO}_{2} \mathrm{l} / \mathrm{kg}$.

Oxygen consumption was measured using a closedcircuit spirometer system. A tidal volume was delivered to the animal from ventilator-driven slave bellows and passively expired back into the circuit using one-way valves to direct flow. $\mathrm{CO}_{2}$ was removed from the circuit by a $\mathrm{CaOH}$ scrubber and replaced with $\mathrm{O}_{2}$ from a volumetric spirometer.

For each of the five dogs, a data set consisted of hemoglobin saturation for arterial and venous blood, $P_{\mathrm{a}} \mathrm{O}_{2}$, $P_{\mathrm{v}} \mathrm{O}_{2}, \mathrm{CO}, \mathrm{VO}_{2}$, and vital signs including pulmonary and systemic blood pressures. $V \mathrm{O}_{2}$ was monitored for $10 \mathrm{~min}$ during the data set collection. The final $V_{2}$ value was obtained by dividing the 10 -min value by a factor of 10 and converting that value to standard temperature and pressure. Oxygen consumption was standardized per unit weight using the formula $V \mathrm{O}_{2}=\left(\mathrm{ml} \mathrm{O}_{2}\right.$ consumed/ $\min *$ STPD correction factor $/ \mathrm{kg}$.

The NE infusion was prepared fresh for each experiment by mixing one ampule $(4 \mathrm{mg})$ Levophed bitartate in $500 \mathrm{ml} \mathrm{LR}$. NE was infused into each dog at rates of $0.04,0.08,0.12,0.16,0.24,0.32$, and $0.40 \mu \mathrm{g} / \mathrm{kg} / \mathrm{min}$. Dosages were chosen to span the range used clinically. At each concentration of the drug as well as at a baseline control before and after drug infusion, a data set was collected. Twenty-five minutes was allowed between the initial infusion of NE at each concentration and the commencement of data collection. During the time of the data collection all animals were in a steady state. The NE was administered using an IVAC 565 Neonate variable pressure pump at the various concentrations discussed above. The drug was infused into the superior vena cava via the proximal port of the pulmonary artery catheter. Drug doses were increased and then decreased incrementally, not in a randomized fashion. The short

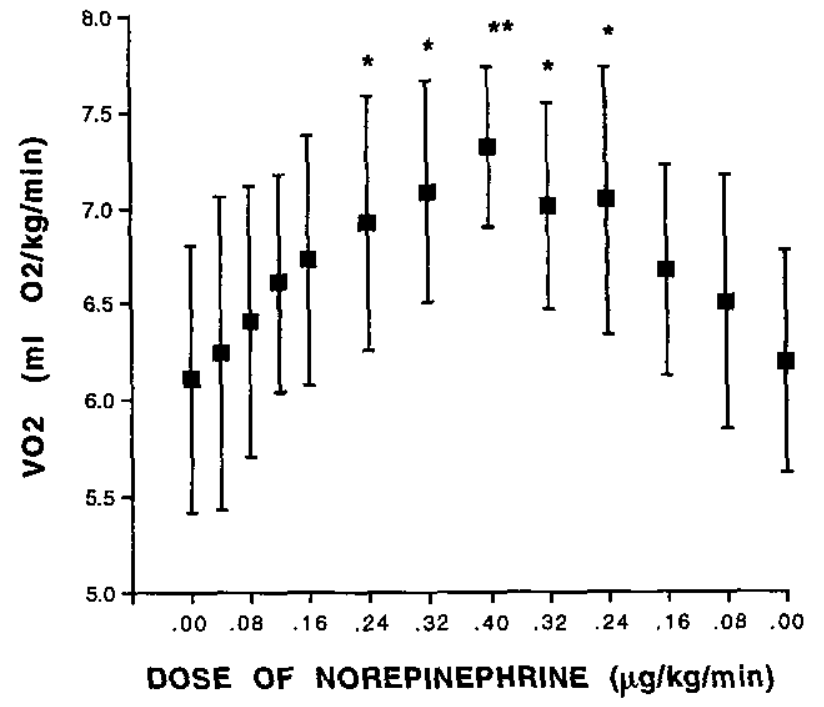

FIG. 1. The effect of norepinephrine (NE) dosage on oxygen consumption $\left(V_{2}\right)(P<0.001$ by repeated measures analysis of variance; ${ }^{*} P<0.05,{ }^{* *} P<0.01$ when compared to baseline by paired $t$ test).

onset of action and half-life of norepinephrine allows appropriate assessment of drug effect with incremental dosing. Stable drug response was achieved after $10 \mathrm{~min}$, and, as mentioned, samples were taken at $25 \mathrm{~min}$.

Arterial and venous blood gas samples were analyzed using an Instrumentation Laboratory Model $282 \mathrm{Co}-\mathrm{ox}$ imeter with a canine chip and a Radiometer ABL-30 blood gas analyzer. The oxyhemoglobin saturation and oxygen content were calculated using $1.39 \mathrm{ml} \mathrm{O}_{2} / \mathrm{g} \mathrm{Hb}$ as the oxygen combining capacity of canine hemoglobin [8].

To assess the effects of $\mathrm{NE}$ on the $V \mathrm{O}_{2}, D \mathrm{O}_{2}, V \mathrm{O}_{2} /$ $\mathrm{DO}_{2}, \mathrm{CO}, \mathrm{MSBP}$, and $\mathrm{SVO}_{2}$, data were analyzed for significant trends using the one-way repeated measures analysis of variance. Paired $t$ test analysis was utilized to compare individual dose responses with the baseline response. All values were expressed as the mean $\pm 1 \mathrm{SD}$.

\section{RESULTS}

Oxygen consumption versus the dose of NE $(\mu \mathrm{g} / \mathrm{kg} /$ $\mathrm{min}$ ) is shown in Fig. 1. The baseline oxygen consumption of canines receiving no NE infusion was $6.1 \pm 0.7 \mathrm{ml}$ $\mathrm{O}_{2} / \mathrm{kg} / \mathrm{min}$. The oxygen consumption at a dose of 0.40 $\mu \mathrm{g} / \mathrm{kg} / \mathrm{min}$ was increased at $7.3 \pm 0.4 \mathrm{ml} \mathrm{O} / 2 / \mathrm{kg} / \mathrm{min}$ when compared to the baseline $(P$ value $<0.001$ by repeated measures analysis of variance). Variability of $V \mathrm{O}_{2}$ is not a function of variation in dog size since all infusions are normalized to units of $\mathrm{mg} / \mathrm{kg} / \mathrm{min}$. However, baseline metabolism and response to dopamine may vary considerably between animals, resulting in the wide standard deviation of the mean that is demonstrated. However, trends within individual dogs were similar, resulting in highly significant changes in $\mathrm{VO}_{2}$, 


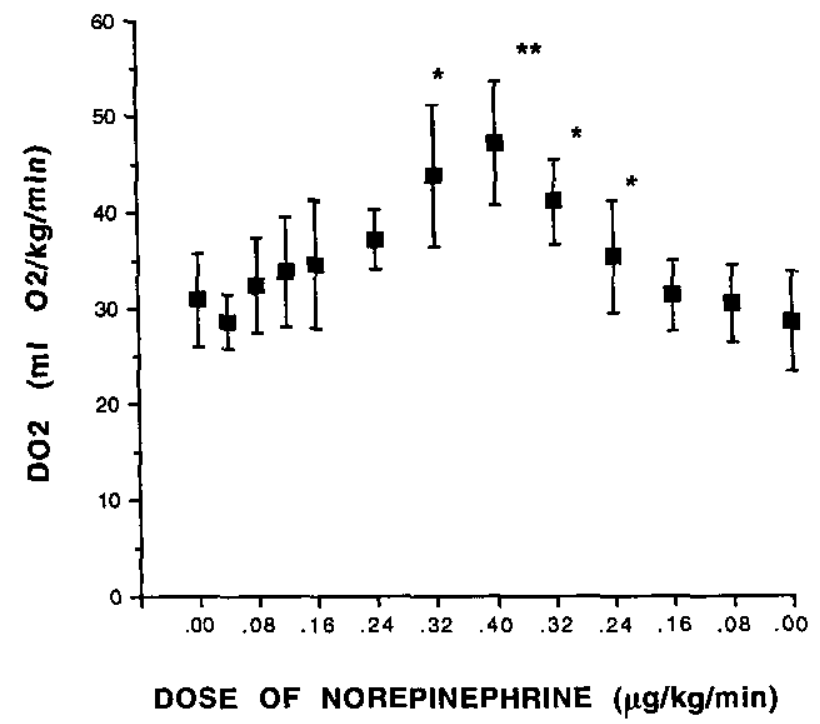

FIG. 2. The effect of norepinephrine (NE) dosage on oxygen delivery $\left(D_{2}\right)\left(P<0.001\right.$ by repeated measures analysis of variance; ${ }^{*} P$ $<0.05,{ }^{* *} P<0.01$ when compared to baseline by paired $t$ test).

$D \mathrm{O}_{2}$, and other physiologic parameters as measured by analysis of variance. Stepwise decrease in NE dose resulted in a gradual reduction in $V \mathrm{O}_{2}$ with the average $V \mathrm{O}_{2}$ value $=6.0 \pm 0.2 \mathrm{ml} \mathrm{O} / \mathrm{kg} / \mathrm{min}$ after discontinuation of NE. This $V \mathrm{O}_{2}$ was not significantly different from the original baseline value. This illustrated that the $V \mathrm{O}_{2}$ increase evident in our experiment was due to a dose-related effect and not an effect of prolonged and continuous NE infusion. This design helped to eliminate the possible bias present with a continuous sequential infusion protocol.

Figure 2 illustrates the relationship of $D \mathrm{O}_{2}$ versus dose of $\mathrm{NE}(\mu \mathrm{g} / \mathrm{kg} / \mathrm{min})$. The baseline $D_{2} \mathrm{O}_{2}$ prior to receiving any $\mathrm{NE}$ was $30.9 \pm 4.9 \mathrm{ml} \mathrm{O} / 2 / \mathrm{kg} / \mathrm{min}$, which increased to $47.1 \pm 6.5 \mathrm{ml} \mathrm{O}_{2} / \mathrm{kg} / \mathrm{min}$ at an NE dose of $0.4 \mu \mathrm{g} / \mathrm{kg} / \mathrm{min}$ $(P<0.001$ by repeated measures analysis of variance). With reduction of NE infusion dose as per protocol, all $\mathrm{DO}_{2}$ values demonstrated an incremental decrease to baseline levels $(28.6 \pm 5.3 \mathrm{ml} \mathrm{O} / 2 / \mathrm{kg} / \mathrm{min})$. This showed that the $\mathrm{DO}_{2}$ increases evident in our experiments were not due to prolonged and continuous NE infusion, but, rather, due to a dose-related effect.

Oxygen delivery divided by respective oxygen consumption versus dose of $\mathrm{NE}$ infused is shown in Fig. 3 . The mean control $D_{2} / V O_{2}$ ratio was $5.0 \pm 0.5$. The $\mathrm{DO}_{2} / \mathrm{VO}_{2}$ ratio significantly increased to $6.4 \pm 0.6$ during $\mathrm{NE}$ infusion at $0.04 \mu \mathrm{g} / \mathrm{kg} / \mathrm{min}(P<0.05$ by analysis of variance). With incremental reduction in the dose of $\mathrm{NE}$ infusion the $\mathrm{DO}_{2} / V \mathrm{O}_{2}$ ratio decreased to near baseline $(4.8 \pm 0.8)$.

Figure 4 reveals the relationship of $\mathrm{SVO}_{2}$ with the dose of $\mathrm{NE}(\mu \mathrm{g} / \mathrm{kg} / \mathrm{min})$. The mixed venous oxygen saturation should fairly closely track the $\mathrm{DO}_{2} / \mathrm{VO}_{2}$ ratio (Fig. 3 ), which it does. The average control $\mathrm{SVO}_{2}$ was $76.2 \pm$

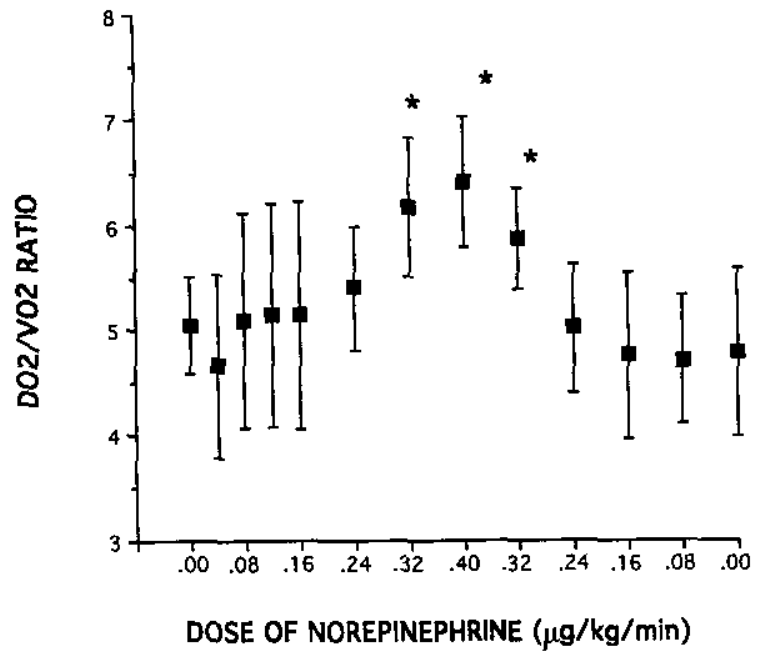

FIG. 3. The effect of norepinephrine (NE) dosage on the oxygen delivery/oxygen consumption ratio $\left(D \mathrm{O}_{2} / V \mathrm{O}_{2}\right)(P<0.001$ by repeated measures analysis of variance; ${ }^{*} P<0.05$ when compared to baseline by paired $t$ test).

$4.4 \%$ and the $\mathrm{SVO}_{2}$ significantly increased to $81.3+$ $1.8 \%$ during $\mathrm{NE}$ infusion at $0.4 \mu \mathrm{g} / \mathrm{kg} / \mathrm{min}(P<0.01$ by repeated measures analysis of variance). The $\mathrm{SVO}_{2}$ decreased to baseline levels $(74.6 \pm 2.8 \%)$ after incremental reduction in $\mathrm{NE}$ infusion.

The relationship between the MSBP and the dose of $\mathrm{NE}$ is illustrated in Fig. 5. The mean control was $114 \pm$ $22 \mathrm{~mm} \mathrm{Hg}$ prior to the onset of $\mathrm{NE}$ administration. Infusion with $0.08,0.12,0.16,0.24,0.32$, and $0.40 \mu \mathrm{g} / \mathrm{kg} / \mathrm{min}$ NE showed statistically significant increases in MSBP compared to no drug infusion $(P<0.001$ by repeated measures analysis of variance). At the end of each exper-

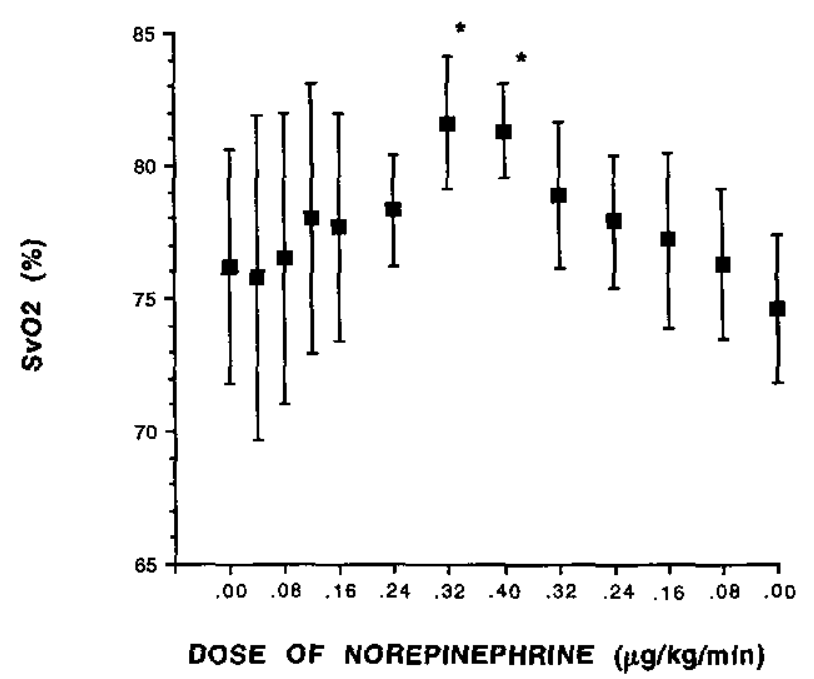

FIG. 4. The effect of norepinephrine (NE) dosage on mixed venous saturation $\left(\mathrm{SVO}_{2}\right)$. As expected, the changes in $\mathrm{SVO}_{2}$ fairly closely parallel the changes in the $\mathrm{DO}_{2} / \mathrm{VO}_{2}$ ratio shown in Fig. $3(P<$ 0.001 by repeated measures analysis of variance; ${ }^{*} P<0.05$ when compared to baseline by paired $t$ test). 


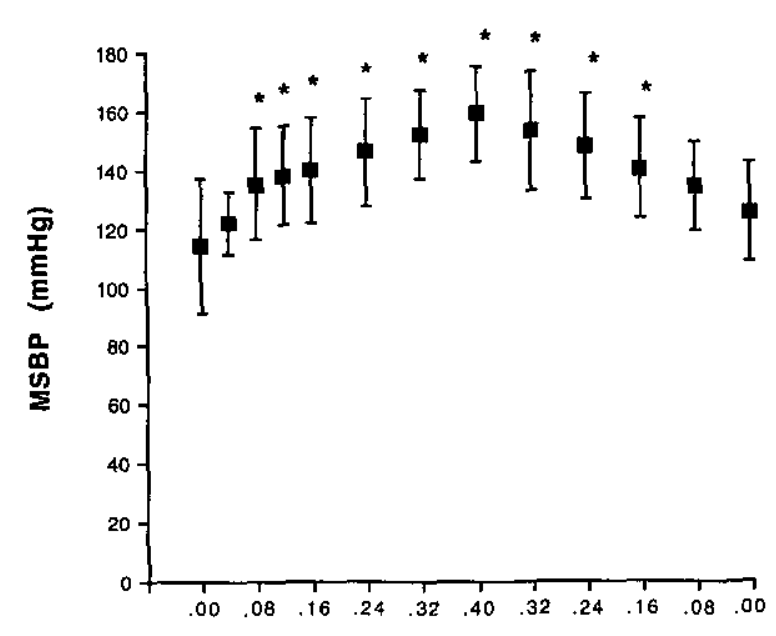

DOSE OF NOREPINEPHRINE $(\mu \mathrm{g} / \mathrm{kg} / \mathrm{min})$

FIG. 5. The effect of norepinephrine (NE) dosage on mean systemic blood pressure (MSBP) $(P<0.001$ by repeated measures analysis of variance; ${ }^{*} P<0.05$ when compared to baseline by paired $t$ test).

iment, an incremental decrease in MSBP for each animal was observed down to near baseline values (125 \pm 17), illustrating that the changes seen in the MSBP during the experiment were dose-related.

Figure 6 demonstrates the mean cardiac output at each NE dose level. The mean CO level for animals with no NE administered was $2.11 \pm 0.42$ liters $/ \mathrm{min}$. The $\mathrm{CO}$ was significantly changed at $3.08 \pm 0.36 \mathrm{liters} / \mathrm{min}$ during intravenous infusions of $0.40 \mu \mathrm{g} / \mathrm{kg} / \mathrm{min} \mathrm{NE}(P<$ 0.05 by analysis of variance). After incremental reduction of NE infusion, the $\mathrm{CO}$ fell to baseline levels (2.31 \pm 0.67), demonstrating that the changes in $\mathrm{CO}$ during the experiment were not from continuous and prolonged administration of NE, but rather a dose-related phenomenon.

\section{DISCUSSION}

The current investigation is important because, in the clinical setting, the administration of NE (as well as other inotropes) is generally guided by blood pressure or cardiac output data without great regard for oxygen consumption and delivery relationships. The goal of inotropic drugs is to increase $\mathrm{DO}_{2}$ by increasing cardiac output, thereby maximizing the $D_{2} / \mathrm{VO}_{2}$ ratio. But if a drug dose increases $V \mathrm{O}_{2}$ in excess of $\mathrm{DO}_{2}$, it is deleterious despite any increase in blood pressure, $\mathrm{CO}$, or $\mathrm{DO}_{2}$. As of yet, little is known regarding the effects of inotropes on total body $\mathrm{VO}_{2}$, and the relationships between $\mathrm{DO}_{2}$ and $V \mathrm{O}_{2}$ in the intact animal have rarely been studied.

Investigators have previously demonstrated dose-related increases in total body $V \mathrm{O}_{2}$ during NE administration in canines [10,11], pigs [12], and humans [13]. The results of the present investigation are consistent with these previous findings. Additionally, dopamine (DA) administration has been shown to significantly increase total body $V \mathrm{O}_{2}$ in dogs [4] and humans [14].
Total body $\mathrm{DO}_{2}$ has been studied in humans infused with various doses of $\mathrm{NE}$ with conflicting results. Some researchers have shown $\mathrm{NE}$ not to affect $\mathrm{CO}$ and $D \mathrm{O}_{2}[9$, $15,16]$, while others reported significant decreases in $\mathrm{CO}$ $[16,17]$. Tuckman and Finnerty [18] and Barcroft and Starr [17] studied the action of NE on CO in man at NE levels of $0.05 \mu \mathrm{g} / \mathrm{kg} / \mathrm{min}$ and approximately $0.14 \mu \mathrm{g} / \mathrm{kg} /$ min. They found either no significant changes or slight decreases in $\mathrm{CO}$. These results are consistent with the present study since significant changes in $D^{\circ} \mathrm{O}_{2}$ were not evident at similar NE infusion dosages. In addition, at the $0.04 \mu \mathrm{g} / \mathrm{kg} / \mathrm{min}$ infusion dose in the present study, the $\mathrm{DO}_{2}$ was decreased, although not significantly so. One other investigation documented a decrease in cardiac index in humans during a $0.05 \mu \mathrm{g} / \mathrm{kg} / \mathrm{min} \mathrm{NE} \mathrm{infu-}$ sion [18]. Decreases in cardiac output at these dosage levels may be explained by low NE dosage effects upon $\alpha$-receptor-mediated vasoconstriction which result in an increase in peripheral vascular resistance without proportional effects on myocardial inotropic or chronotropic activity.

Ruttiman et al. [7] studied the effects of DA in humans at various different infusion rates on total body $\mathrm{DO}_{2}$ and $\mathrm{VO}_{2}$. These investigators illustrated that $V \mathrm{O}_{2}$ increased significantly only at the highest DA infusion rates, but not at the lowest administration rate $(2.5 \mu \mathrm{g} /$ $\mathrm{kg} / \mathrm{min}$ ). Additionally, $\mathrm{DO}_{2}$ was shown to significantly increase at all dosage levels when compared with the control. These investigators noted at all rates of infusion studied that the increase in $\mathrm{DO}_{2}$ observed was greater than the increase in $V \mathrm{O}_{2}$. To our knowledge, other studies examining the relationship of total body $\mathrm{DO}_{2}$ and $V \mathrm{O}_{2}$ have yet to be performed with this or other inotropes.

In the present investigation, NE was chosen as a prototype catecholamine to study the relationship between

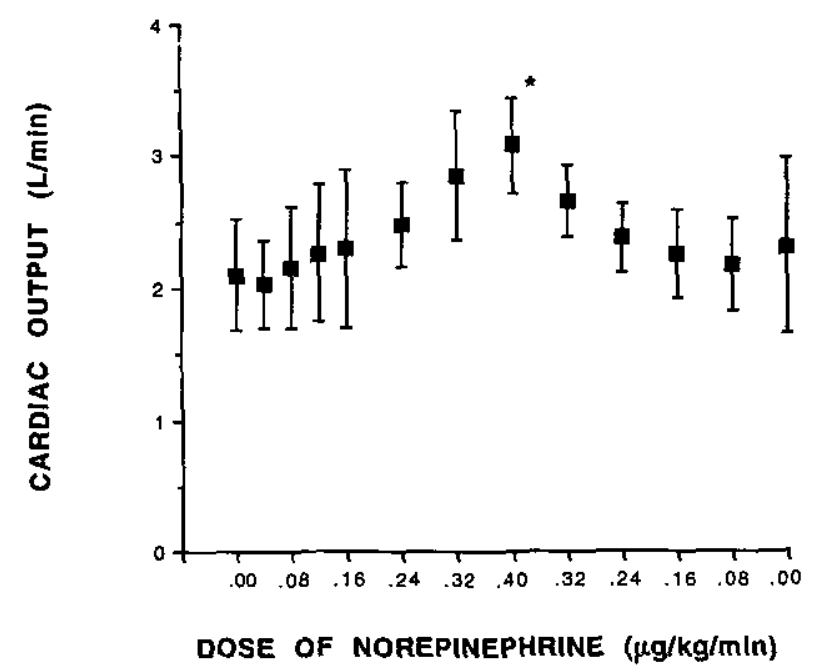

FIG. 6. The effect of norepinephrine (NE) dosage on cardiac output $\left(P<0.001\right.$ by repeated measures analysis of variance; ${ }^{*} P<0.05$ when compared to baseline by paired $t$ test). 
total body $\mathrm{DO}_{2}$ and $\mathrm{VO}_{2}$ and to evaluate the efficacy of those hemodynamic variables typically utilized to assess $\mathrm{NE}$ dosing as monitors of the $\mathrm{DO}_{2} / \mathrm{VO}_{2}$ relationship. $\mathrm{NE}$ administration resulted in a significant dose-dependent increase in $\mathrm{VO}_{2}$ and blood pressure. The increase in systemic vascular resistance appeared to counter any inotropic effect realized at lower $\mathrm{NE}$ doses so that $\mathrm{CO}$ and $\mathrm{DO}_{2}$ were not significantly increased at those doses. Therefore, minimal advantage to oxygen utilization physiology was observed at lower doses of NE even though blood pressure was increased at all doses. At the infusion rate of $0.04 \mu \mathrm{g} / \mathrm{kg} / \mathrm{min}$, an increase in $V_{2}$ relative to $\mathrm{DO}_{2}$ was documented, although statistical significance was not achieved. Administration of NE at this dose may prove to be deleterious rather than helpful. Even though the effects of norepinephrine resulted in an improvement in the $D_{2} / V \mathrm{O}_{2}$ ratio with increasing $\mathrm{NE}$ doses, a state of hypermetabolism (increased $V_{2}$ ) still existed. The implications of the induced hypermetabolism and these $\mathrm{DO}_{2} / \mathrm{VO}_{2}$ relationships during $\mathrm{NE}$ administration may be even more important in the patient with compromised cardiac function. Certainly, increasing $\mathrm{VO}_{2}$ in the patient with little cardiac reserve and minimal ability to increase $\mathrm{CO}$ or $\mathrm{DO}_{2}$ would not be beneficial. Other inotropes with less effect on $\mathrm{VO}_{2}$ might be more effective in this situation at improving the $\mathrm{DO}_{2} / \mathrm{VO}_{2}$ ratio, even if they were less potent inotropic agents. Research into this area is currently being pursued in the laboratory. Additional research is being directed at more clearly defining cardiac specific $\mathrm{DO}_{2}$ and $\mathrm{VO}_{2}$ responses to inotropes as well as $\mathrm{DO}_{2}$ and $\mathrm{VO}_{2}$ changes in animals that are physiologically stressed in order to further understand the effects of these drugs on physiologic needs.

The mixed venous oxygen saturation is a physiologic parameter which may be continuously monitored in critically ill patients. In this study on normal dogs, cardiac output appeared to trend in a fashion similar to that of the $\mathrm{SVO}_{2}$. Once again, such may not be the case in the patient with little cardiac reserve. However, the data from this study would suggest that the $\mathrm{SVO}_{2}$, which reflects the ratio of $D \mathrm{O}_{2}$ to that of $\mathrm{VO}_{2}$, would serve as an excellent continuous monitor of the effect upon $\mathrm{DO}_{2}$ in relation to that of $\mathrm{VO}_{2}$ during norepinephrine administration.

\section{REFERENCES}

1. Malloy, W. D., Lee, K. Y., Girling, L., et al. Treatment of shock in a canine model of pulmonary embolism. Am. Rev. Respir. Dis. 130: $870,1984$.
2. Anderson, W. P., and Harrison, D. T. Blood pressure responses to prolonged infusions of adrenaline and noradrenaline in concious dogs. Clin. Exp. Hypertens. 6(8): 1469, 1984.

3. Cain, S. M. Oxygen delivery and uptake during anemic and hypoxic hypoxia. J. Appl. Physiol. Respir. Environ. Exercise Physiol. 42(2): 228, 1977.

4. Scott, A., Chakrabaft, L., and Hall, G. M. Oxygen transport during dopamine infusion in dogs. Br. J. Anesthesiol. 51: 1011, 1979.

5. Gilbert, E. M., Haupt, M. T., Mandanas, R. Y., et al. The effect of fluid loading, blood transfusion and catecholamine infusion on oxygen delivery and consumption in patients with sepsis. $A m$. Rev. Respir. Dis. 134: 873, 1986.

6. Cilley, R. E., Polley, T. Z., Zwischenberger, J. B., et al. Supply dependency of oxygen consumption. J. Surg. Res. 47(3): 242, 1989.

7. Ruttimann, Y., Chiolero, R., Jequier, E., Breitenstein, E., and Schultz, Y. Effects of dopamine on total oxygen consumption and oxygen delivery in healthy men. Am. J. Physiol. (Endocrinol. Metab.) 257(20): 541, 1989.

8. Dennis, R., and Valeri, C. Measuring percent oxygen saturation of hemoglobin, percent carboxyhemoglobin and methemoglobin, and concentrations of total hemoglobin and oxygen in blood of man, dog, and baboon. Clin. Chem. 12(8): 695, 1980.

9. Molloy, D. W., Lee, K. Y., Jones, D., et al. Effects of noradrenaline and isoproterenol on cardiopulmonary function in a canine model of acute pulmonary hypertension. Chest $\mathbf{8 8}(3)$ : 432, 1985.

10. Blatties, C. M., and Lutherer, L. $O$. Reduction by moderate hypoxia of the calorigenic action of catecholamines in dogs. J. Appl. Physiol. 36(3): 337, 1974.

11. Cain, S. M., and Chapler, C. K. Effects of norepinepherine and alpha-block on $\mathrm{O}_{2}$ uptake and blood flow in dog hind limb. Am. Physiol. Soc. 51(5): 1245, 1981.

12. Jamieson, L., and Stribling, D. Effects of noradrenaline on oxygen consumption and tissue blood flow in young pigs. Can. $J$. Physiol. Pharmacol. 62: 136, 1983.

13. Svedmyr, N. The action of triodothyronine on some effects of adrenaline and noradrenaline in man. Acta. Pharmacol. Toxicol. 24: 203, 1966.

14. Campbell, I. T., Regan, C., Duckworth, R., Fairhurst, J., Maycock, P., and Frayn, K. N. The effects of dopamine at doses of $2-10 \mu \mathrm{g} / \mathrm{kg}$ body weight per minute on metablic rate in normal man. Proc. Nutr. Soc. 47: 60A, 1987. [Abstract].

15. Goldenberg, M., Pines, K. L., Boldwin, E. F., et al. The hemodynamic response of man to norepinephrine and epinephrine and its relation to the problem of hypertension. $A m J$. Med. 5: 792, 1948.

16. Fowler, N. O., Westcott, R. N., Scott, R. C., and Mcguire, J. The effect of norepinephrine upon pulmonary arterial resistance in man. J. Clin. Invest. 30(5): 517, 1951.

17. Barcroft, H., and Starr, I. Comparison of the actions of adrenaline and noradrenaline on the cardiac output in man. Clin. Sci. (London) 10(3): 295, 1951.

18. Tuckman, J., and Finnerty, F. A. Cardiac index during intravenous levorterenol infusion in man. Circ. Res. 8: 988, 1959. 